

\title{
SOSIALISASI MODIFIKASI MESIN KETINGTING DI POSYANTEK DAN KELOMPOK NELAYAN PESISIR PANTAI PENGHULU AGUNG AMPENAN KOTA MATARAM
}

\section{Ketingting Machine modification socialization in Posyantek dan Fisherman Group of Penghulu Agung Coastal, Sub District Ampenan, Mataram City}

\author{
I Made Suartika, I Dewa Ketut Okariawan, Made Wijana, Wawan Saputra \\ Program Studi Teknik Mesin Universitas Mataram \\ Jl. Majapahit Nomor 62 Kota Mataram, NTB
}

Alamat korespondensi : imadesuartika@unram.ac.id

(Tanggal Submission: 20 September 2021, Tanggal Accepted : 15 Desember 2021)

\begin{abstract}
Kata Kunci : Abstrak :
modifikasi Dalam operasionalnya terutama melaut di malam hari, nelayan tradisional mesin menggunakan aki untuk mensuplai daya lampu penerangan dalam aktifitas ketingting, light fishing. Untuk penerangan 4 lampu dengan daya 10 watt, nelayan nelayan menggunakan aki 12 volt yang hanya mampu bertahan selama 4 jam, tradisional, sedangkan waktu melaut rata-rata 12 jam/hari. Untuk memenuhi kebutuhan posyantek, kekurangan arus listrik, nelayan menggunakan aki tambahan atau mencharge alternator aki yg membutuhkan biaya dan waktu yang tinggi. Salah satu solusi yang dapat dilakukan terhadap permasalahan tersebut adalah dengan memodifikasi mesin ketinting. Kegiatan pengabdian kepada masyarakat ini bertujuan untuk memodifikasi mesin perahu ketingting milik nelayan tradisional di Pantai Ampenan. Hal tersebut bermanfaat bagi para nelayan agar bisa mengisi aki sendiri pada saat operasional di laut. Metode yang digunakan adalah penyuluhan dan sosialisasi. Kegiatan ini dilaksanakan dengan Kerjasama Balitbang kota Mataram, penyuluh Dinas Perikanan dan Kelautan kota Mataram, dan Posyantek Ampenan. Hasil dari kegiatan adalah dihasilkannya modifikasi mesin ketinting dengan penambahan alternator yang dapat mengisi aki dalam waktu 7 sampai dengan 8 jam dengan kapasitas aki 45 Ah. Dengan penambahan alternator maka konsumsi bahan bakar menjadi 0,5 liter/jam dari 0,38 lietr/jam sebelum modifikasi. Biaya yang dibutuhkan untuk melakukan modifikas kisaran Rp 500.000 sampai dengan Rp 600.000 perunit sesuai dengan spesifikasi bahan yang digunakan. Kesimpulannya kegiatan ini sangat membantu untuk meningkatkan efisiensi dan efektifitas operasional para nelayan.
\end{abstract}


Panduan sitasi / Citation guidance (APPA $7^{\text {th }}$ edition) :

Suartika, I.M., Okariawan, I.D.K., Wijana, M., \& Saputra, W. (2021). Sosialisasi Modifikasi Mesin Ketingting Di Posyantek Dan Kelompok Nelayan Pesisir Pantai Penghulu Agung Ampenan Kota Mataram. Abdi Insani, 8 (3), 295-301. http://doi.org/10.29303/abdiinsani.v8i3.444

\section{PENDAHULUAN}

Nelayan adalah masyarakat yang pekerjaannya menangkap ikan atau biota lainnya di perairan. Perairan yang menjadi daerah aktivitas nelayan ini dapat merupakan perairan tawar, payau maupun laut. Di negara-negara berkembang seperti di Asia Tenggara atau di Afrika, masih banyak nelayan yang menggunakan peralatan yang sederhana dalam menangkap ikan (Anonim, 2021; Listyawati, 2016; Rubiono \& Martaviano, 2020; Suartika et al., 2013). Nelayan di negara-negara maju biasanya menggunakan peralatan modern dan kapal yang besar yang dilengkapi teknologi canggih (Akhayari, 2018).

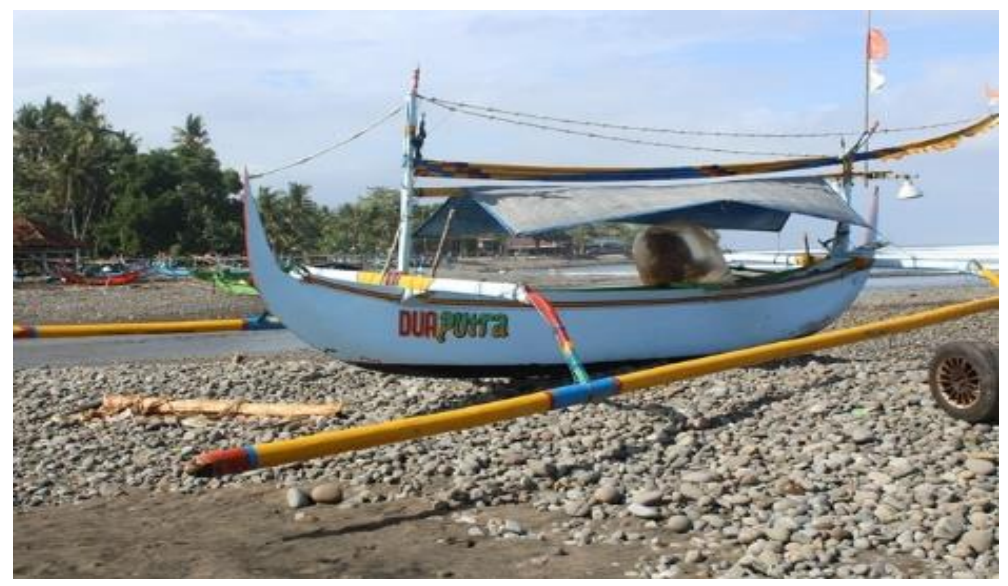

Gambar 1. Nelayan Tradisional



Gambar 2. Nelayan Modern

Dalam menjalankan kegiatan penangkapan ikan para nelayan menggunakan beberapa jenis armada tangkap yaitu perahu tanpa motor, perahu motor tempel dan kapal motor. Perbedaan armada 
tangkap dan peralatan kerja yang digunakan oleh nelayan berarti adanya perbedaan teknologi dalam menangkap ikan yang dalam penelitian ini dikelompokkan dalam teknologi modern dan teknologi tradisional. Pada gambar 2 di atas, nelayan yang menggunakan teknologi modern ditandai dengan penggunaan kapal bermotor sebagai armada tangkap yang disertai dengan global positioning system (GPS) sebagai penunjuk arah dan fish finder (pendeteksi keberadaan ikan). Sedangkan pada gambar 1 menunjukkan nelayan yang menggunakan teknologi tradisional armada tangkap yang digunakan tidak dilengkapi dengan GPS dan fish finder. Faktor lain yang dapat mempengaruhi hasil produksi (tangkapan ikan) oleh nelayan adalah musim. Dikemukakan oleh Srikanthan (2013), bahwa meskipun kemajuan teknologi di abad ke-20, cuaca dan musim masih faktor kunci dalam menentukan produksi perikanan ((Munandar et al., 2020).

Dalam menjalankan kegiatan penangkapan ikan para nelayan di Kota Mataram khususnya di lingkungan Karang Panas, Kecamatan Ampenan Selatan menggunakan beberapa jenis armada tangkap yaitu perahu tanpa motor, perahu motor tempel dan kapal motor. Perbedaan armada tangkap dan peralatan kerja yang digunakan oleh nelayan berarti adanya perbedaan teknologi dalam menangkap ikan yang dalam penelitian ini dikelompokkan dalam teknologi modern dan teknologi tradisional. Nelayan yang menggunakan teknologi modern ditandai dengan penggunaan kapal bermotor sebagai armada tangkap yang disertai dengan global positioning system (GPS) sebagai penunjuk arah dan piranti modern lainnya. Sedangkan nelayan-nelayan yang menggunakan teknologi tradisional armada tangkap yang digunakan hanya menggunakan mesin ketinting saja dan tidak menggunakan teknologi modern. Faktor lain yang dapat mempengaruhi hasil produksi (tangkapan ikan) oleh nelayan adalah musim. Dikemukakan oleh Srikanthan (2013), bahwa meskipun kemajuan teknologi di abad ke-20, cuaca dan musim masih faktor kunci dalam menentukan produksi perikanan.

Berdasarkan hasil observasi dan wawancara dengan nelayan di lapangan, kurang maksimalnya kegiatan operasional nelayan di saat-saat musim ikan disebabkan oleh tidak optimalnya melaut di malam hari. Kurang optimalnya melaut pada malam hari dikarenakan kurang memadainya piranti pendukung seperti penyuplai daya lampu atau baterai yang digunakan hanya mampu menyumplai daya lampu 5 sampai 6 jam saja, sedangkan untuk kegiatan menangkap ikan butuh waktu yang lebih lama untuk mendapatkan hasil yang cukup (Suartika et al., 2020; Yudhyadi et al., 2019).

Beberapa modifikasi mesin ketinting yang telah dilakukan seperti penggunaan tenaga surya (Raleta et al., 2018) tapi masih belum bisa optimal karena intensitas matahari yang terbatas. Untuk itu dilakukan modifikasi mesin ketinting dengan menambahkan alternator bertujuan untuk membantu masyarakat di Lingkungan Karang Panas, Kecamatan Ampenan Selatan, Kota Mataram dalam memenuhi kebutuhan daya lampu untuk penerangan pada saat melakukan aktifitas menangkap ikan pada malam hari. Mesin ketinting dikopel dengan pully di poros panjangnya, dan pully tersebut dihubungkan dengan alternator menggunkan V-belt, sehingga pada saat mesin ketinting dihidupkan maka alternator akan ikut berputar dan akan mengisi aki/baterai. Dengan mencatat pemakaian daya listrik, lama pengisian aki, dan lama penggunaan aki dalam sekali pengisian. Pada saat nelayan melakukan aktifitas pada siang hari dan tidak menggunakan lampu, alternator akan mengisi aki dan aki siap digunakan pada malam harinya dengan keadaan penuh.

\section{METODE KEGIATAN}

Metode yang digunakan pada kegiatan pada kegiatan ini adalah dengan melakukan sosialisasi modifikasi mesin ketingting. Kegiatan sosialisasi dilaksanakan bekerjasama dengan Balitbang-Dinas 
perikanan dan kelautan kota mataram serta posyantek ampenan. Sosialisasi dilakukan dalam dua tahap yaitu; pertama sosialisasi di Posyantek Ampenan dan kedua di kelompok nelayan. Posyantek merupakan posko pelayanan teknologi tepat guna yang dibentuk oleh Balitbang Kota Mataram di setiap kecamatan yang bertujuan untuk memberikan pelayanan kepada masyarakat terkait permasalahan teknologi tepat guna.

\section{HASIL DAN PEMBAHASAN}

Hasil modifikasi mesin perahu ketinting seperti yang ditunjukan dalam gambar 3 diketahui bahwa dengan menambahkan rangkaian alternator maka nelayan dapat mengisi daya aki ketika mesin dalam posisi hidup. Dan Ketika aki sudah terisi penuh maka arus akan berhenti mengalir ke aki yang diatur oleh regulator.
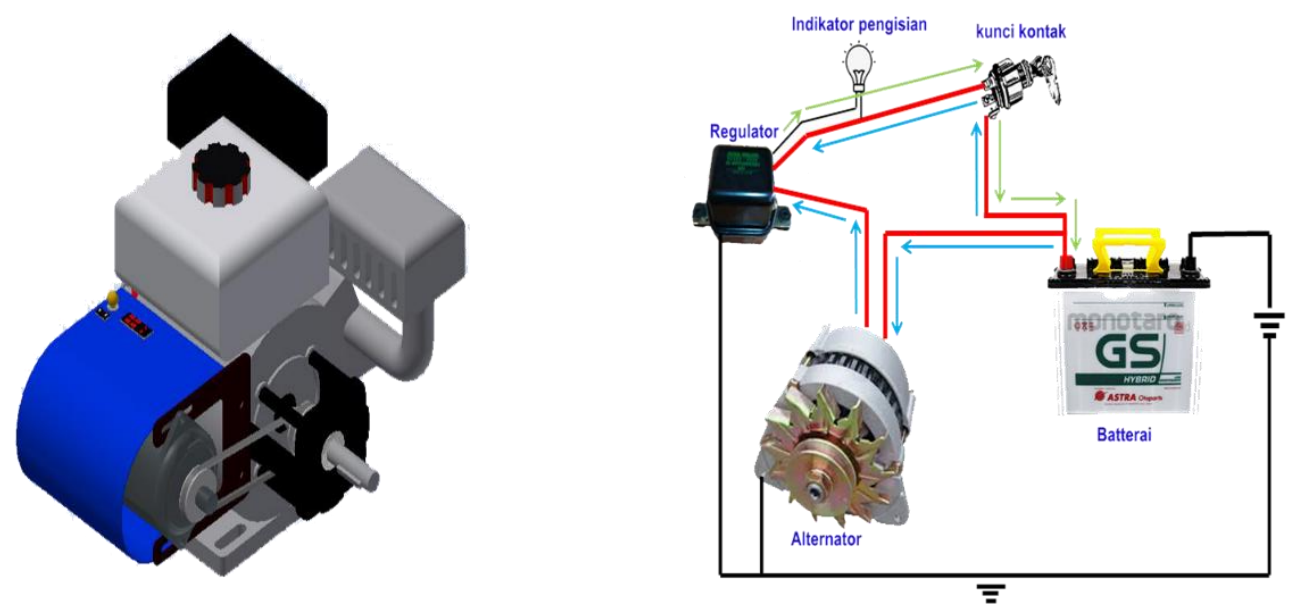

Gambar 3. Modifikasi mesin ketingting

Dari hasil percobaan di laboratorium untuk mengisi aki dengan kapasitas 45 Ah dibutuhkan waktu rata-rata selama 7 sampai dengan 8 jam. Sedangkan pemakaian aki bertahan dalam waktu 8 sampai dengan 9 jam untuk mensuplai daya lampu 44 watt.

Hasil modifikasi tersebut kemudian disosialisasikan ke Posyantek Ampenan yang dilaksanakan pada tanggal 11 Oktober 2021 di rumah ketua posyantek kecamatan Ampenan bapak Theo. Peserta yang hadir adalah dari pihak Unram 4 orang, balitbang kota Mataram 2 orang, dinas perikanan dan kelautan 1 orang, dan dari posyantek sendiri 6 orang. Setelah dilakukan presentasi, demontrasi, dan diskusi modifikasi mesin ketingting didapatkan beberapa masukan dan kesepakatan yaitu; (1) pihak balitbang, dinas kelautan, posyantek sangat mengapresiasi inovasi mesin ketingting tersebut, (2) perlu dilakukan perhitungan dari segi ekonomisnya inovasi yang dibuat, dan (3) disepakati bahwa sosialisasi ke kelompok nelayan penghulu agung pada tanggal 13 Oktober 2021. 




Gambar 4. Pelaksanaan sosialisasi di Posyantek Ampenan

Sosialisasi dan demontrasi di kelompok nelayan penghulu agung kecamatan ampenan pada tanggal 13 Oktober 2021 yang berlokasi di Tower Pantai Penghulu Agung yaitu; (1) nelayan sangat tertarik dengan hasil modifikasi mesin ketingting tersebut dan berencana untuk melakukan modifikasi. (2) masukan nelayan terkait cover/tutup alternator menggunakan bahan anti korosi, dan (3) nelayan siap untuk menguji performansi mesin dalam operasional nelayan.

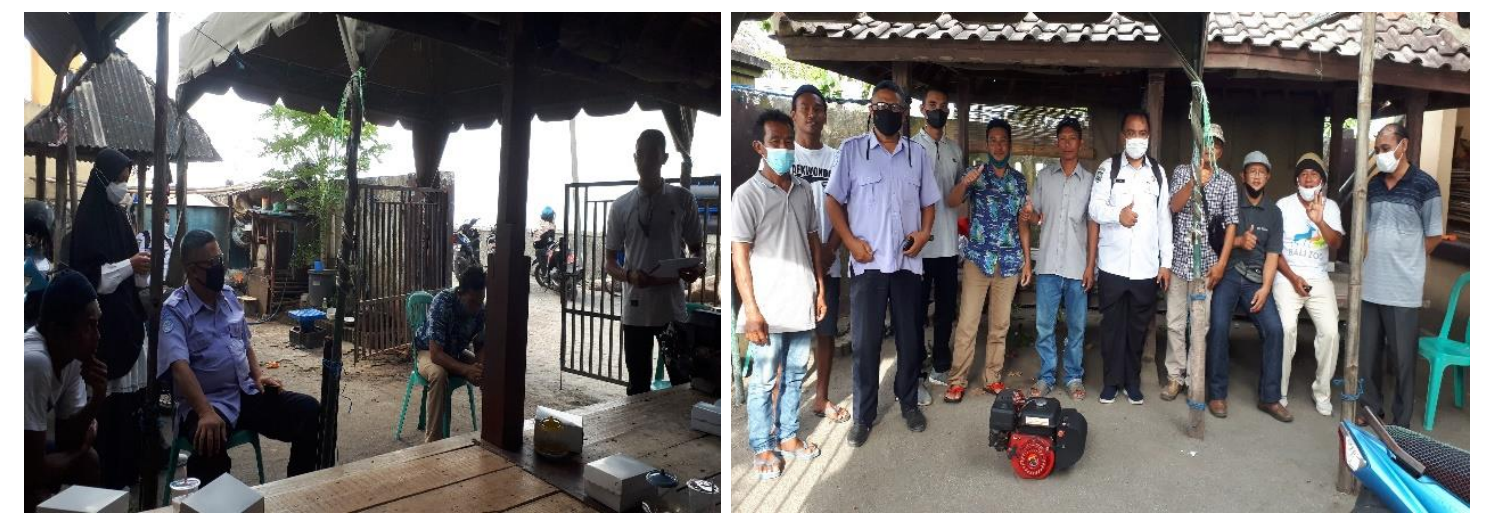

Gambar 5. Pelaksanaan sosialisasi di kelompok nelayan

Berdasarkan masukan-masukan dari para nelayan sebagai pengguna mesin ketinting kemudian dilakukan perbaikan dengan menambahkan penutup mesin seperti yang ditunjukan dalam gambar 6. Adapun biaya yang dibutuhkan untuk melakukan modifikasi mesin berkisar antara Rp 500,000 sampai dengan $\mathrm{Rp} 600,000$ tergantung spesifikasi bahan yang digunakan. 


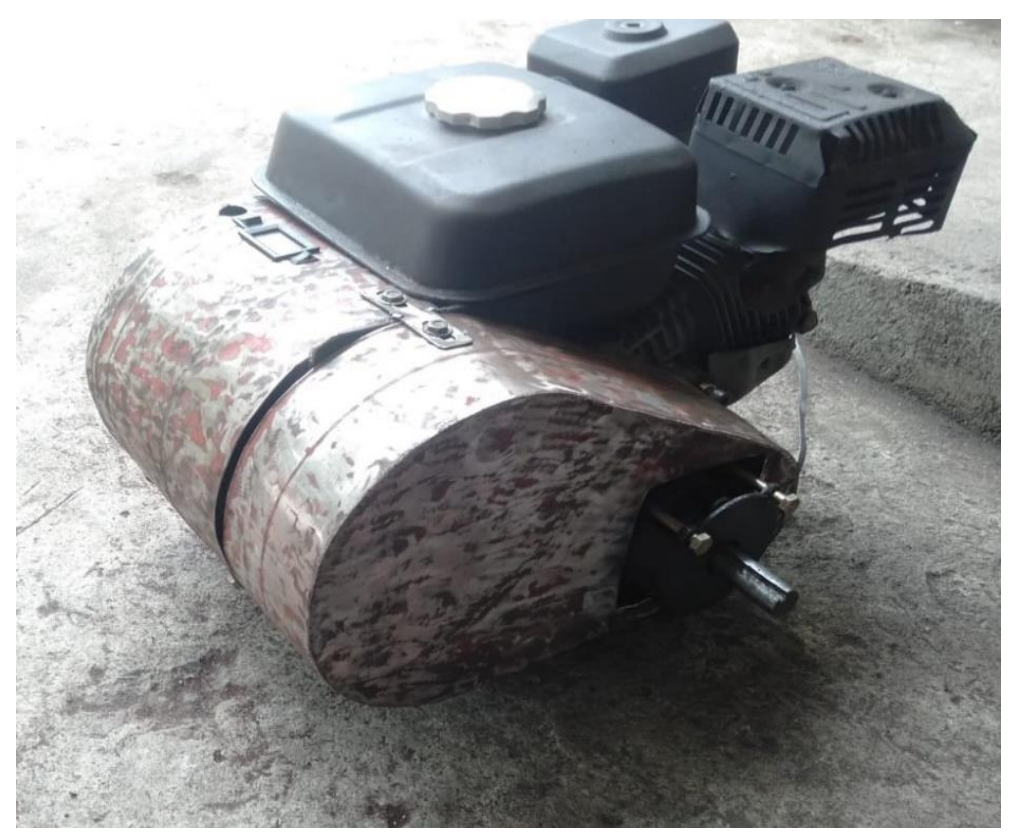

Gambar 6. Hasil modifikasi akhir setelah sosialisasi ke nelayan



Gambar 7. Pengujian performasi mesin di laut pada malam hari

Hasil pengujian di tengah laut seperti ditunjukan dalam gambar 7 bahwa mesin dapat beropaerasi dengan baik. Rata-rata jarak tempuh operasional nelayan untuk melakukan aktifitas adalah $11 \mathrm{~km}$ dengan waktu tempuh 1,57 jam dan konsumsi bahan bakarnya 0,56 lietr/jam. 


\section{KESIMPULAN DAN SARAN}

Kesimpulan dari kegiatan ini adalah sebagai berikut:

1. Dengan menambahkan alternator pada mesin ketinting nelayan dapat mengisi aki pada saat melakukan aktifitas di laut.

2. Pengisian aki dapat dilakukan dalam waktu rata-rata 7-8 jam yang berkapasitas 45 Ah dan konsumsi bahan bakar 0,5 liter/jam.

3. Kebutuhan biaya untuk modifikasi Rp 500.000 sampai dengan Rp 600.000 sesuai dengan spesifikasi bahan yang digunakan.

Saran-saran untuk penelitian/kegiatan lebih lanjut adalah terkait cover atau penutup mesin/komponen alernatornya agar kedap air, mudah dilepas, dan bahan yang tahan terhadap korosi air laut.

\section{UCAPAN TERIMA KASIH}

Penulis mengucapkan terima kasih kepada Balitbang, Dinas Perikanan dan kelautan kota Mataram, dan LPPM yang telah memberi dukungan financial dan fasilitasi terhadap pengabdian ini.

\section{DAFTAR PUSTAKA}

Akhayari, H. (2018). Kenali 10 fakta menarik tentang laut Indonesia. GNFI. https://www.goodnewsfromindonesia.id

Anonim. (2021). Perkembangan nilai produksi perikanan Kota Mataram. Dislutkan NTB. https://dislutkan.ntbprov.go.id/

Listyawati, A. (2016). Strategi penanganan kemiskinan nelayan tradisional. Media Informasi Penelitian Kesejahteraan Sosial, 40(1), 61-70.

Munandar, T., Dadan, \& Darmawan. (2020). Implementasi program pemberdayaan masyarakat miskin pada komunitas nelayan tradisional untuk kesejahteraan sosial ekonomi di Lontar kabupaten Serang. Jurnal Eksistensi Pendidikan Luar Sekolah, 5(2), 126-133.

Raleta, J., Wijaya, N., \& Tambunan, K. (2018). Rancang Bangun Mesin Katinting Tenaga Surya,. In Politeknik Kelautan dan Perikanan, Universitas Manado. Politeknik Kelautan dan Perikanan, Universitas Manado.

Rubiono, G., \& Martaviano, B. S. (2020). Reduksi resiko dan peningkatan efisiensi kerja kelompok nelayan sampan layar di desa Alasrejo kecamatan Wongsorejo kabupaten Banyuwangi, Jati Emas.

Jati Emas (Jurnal Aplikasi Teknik Dan Pengabdian Masyarakat), 4(2), 55-60. https://doi.org/https://doi.org/10.36339/je.v4i2.314

Srikanthan, S. (2013). Dampak Perubahan Iklim terhadap Pengembangan Mata Pencaharian Nelayan, studi kasus desa di pantai Coromandel. Jurnal Humaniora Dan IImu Sosial, 12(6), 49-54.

Suartika, I. M., Padmiatmi, P., Wa, I. C. A., Syahrul, S., \& Wijana, M. (2020). Pemberdayaan Nelayan Pesisir Karang Bangket Kabupaten Lombok Barat. Prosiding PEPADU, 188-192.

Suartika, I. M., Yudhyadi, Okariawan, Chatur, \& Wijana. (2013). Pengentasan Kemiskinan Melalui Pelatihan Perawatan Mesin Perahu Nelayan di Desa Batunampar. Laporan Pengabdian Kepada Masyarakat, BOPTN Universitas Matarram.

Yudhyadi, Okariawan, Suartika, I., \& Chatur. (2019). Design and simulation of boat pulling system to improve productivity of the traditional fishermen in steep coastal region. Jurnal Dinamika Teknik Mesin Unram, 9(1), 31-38. 